\title{
A Comparison of Sexual Function, Psychological Status, and Sociodemographic Characteristics of Turkish Men within Polygamous and Monogamous Marriages
}

\author{
Hasan Çetin Ekerbiçer ${ }^{1}$, Sefa Resim², Erkan Efe ${ }^{2}$, Mustafa Remzi Bahar ${ }^{2}$, \\ Özlem Altunören ${ }^{3}$, Faruk Küçükdurmaz ${ }^{4}$, Can Benlioğlu ${ }^{5}$ \\ 'Department of Public Health, Sakarya University School of Medicine, Sakarya, Turkey \\ ${ }^{2}$ Department of Urology, Kahramanmaraş Sütçü İmam University School of Medicine, Kahramanmaraş, Turkey \\ ${ }^{3}$ Department of Psychiatry, Kahramanmaras State Hospital, Kahramanmaras, Turkey \\ ${ }^{4}$ Department of Urology, Nizip State Hospital, Gaziantep, Turkey \\ ${ }^{5}$ Department of Urology, Adıyaman University School of Medicine, Adiyaman, Turkey
}

Background: A limited number of studies within the literature have entailed objective evaluations of psychological, sexual, and emotional features of women within polygamous marriages. However, there is a lack of studies reporting these features among polygamous and monogamous men.

Aims: The aim of this study was to investigate sociodemographic characteristics, sexual function, and psychological status of polygamously and monogamously married men.

Study Design: Cross-sectional study.

Methods: The study sample comprised two groups: 35 polygamous and 45 monogamous men in Kahramanmaraş Province, Turkey. Door-to-door surveys covered sociodemographic factors and adopted Beck Depression Inventory (BDI), and International Index of Erectile Function - Erectile Function Domain (IIEF-EFD) scales.

Results: Polygamous men showed considerably higher IIEF-EFD scores $(\mathrm{p}<0.05)$. While the median score of IIEFEFD was 25.0 for polygamous men, it was 22.0 for monogamous men. A comparison of the two groups revealed that polygamous men had lower BDI scores. However, the difference between the groups was statistically non-significant $(\mathrm{p}>0.05)$. Odds ratios and $95 \%$ confidence intervals of monogamous men for erectile dysfunction and depression were 14.4 (95\% CI: 3.1-67.5) and 7.4 (95\% CI: 0.9-61.9), respectively. The main reasons for multiple marriages reported by polygamous men, in descending order, were: 1) decreased satisfaction of sexual desires by a wife (37.1\%); 2) falling in love with the second wife $(22.8 \%)$; and 3$)$ incompatibility with the first wife (17.1\%). However, $62.9 \%$ of them responded negatively to the question: "Would you recommend polygamous marriage to other men?"

Conclusion: Our results showed that polygamous men had higher erectile function and lower depression scores than monogamous men. Further studies investigating the effects of polygamy on men's psychosexual function are warranted. Additionally, studies that address the perspectives of offspring and women's expectations within polygamous marriages should be conducted.

Keywords: Beck Depression Inventory, erectile status, polygamy, polygamous men 
Within social anthropology, the use of the term polygamy is related to its derivation from a Greek word meaning "the practice of multiple marriages." It can be defined as any form of marriage in which a person has more than one spouse (1). Several forms of polygamy have been described. Polyandry refers to one woman's marriage to two or more husbands, polygyndry entails the simultaneous marriage of two or more women to two or more men, and polygynandry refers to group marriages (2). Polyandrous marriages constitute a small proportion of polygamous marriages. The prevalence and distribution of polygamy within individual cultures vary according to social class, education, and geographical location. However, it is very rarely practiced as an exclusive form of marriage within western societies and in the rest of world. It is practiced by some Muslims, Hindus, Mormons, and other cultural and religious groups $(3,4)$. Polygamy is illegal in Turkey, and occurs very rarely within Turkish society. However, the practice still exists, mostly in the Kurdish populated southeastern region of the country (5).

A limited number of studies within the literature have entailed objective evaluations of psychological, sexual, and emotional features of women within polygamous marriages. Polygamous marriages have been associated with stress, fear and disparity within the family structure (6). Women in polygamous marriages generally experience varying degrees and types of emotional difficulty such as anger, jealousy, competition, loneliness, unhappiness, and a lack of intimacy with their spouses. However, there is a lack of studies reporting these features among polygamous and monogamous men. The aim of this study is thus to investigate and compare sociodemographic characteristics, and psychological and sexual functions of men within polygamous and monogamous marriages in Kahramanmaraş Province, Turkey.

\section{MATERIALS AND METHODS}

This cross-sectional study was conducted on men within polygamous and monogamous marriages in Kahramanmaraş Province in Turkey's eastern Mediterranean region between April 2011 and February 2014. The study was conducted in accordance with the Declaration of Helsinki. Written informed consent was taken from participants. The Ethics Committee of the Kahramanmaraş Sütçü İmam University School of Medicine approved the study including the consent procedure (Date of approval: 15 April 2011; number: 2011-02/4). A snowball sampling method was used to recruit 35 respondents who were in polygamous marriages. Initially, men who were known to be polygamous were interviewed. Subsequently, individuals known by these respondents to be polygamous were identified and interviewed. A baseline assessment of sociodemographic characteristics, employment status, and comorbid diseases of these men was conducted. Control participants were recruited from family and friends of the patients attending the outpatient department of urology. The control group consisted of 45 men within monogamous marriages with similar characteristics that could affect sexual function, such as accompanying comorbid diseases, smoking, alcohol, and drug habits, and socioeconomic and sociodemographic variables such as age and educational and income levels.

Inclusion criteria for selecting respondents were being married (monogamy or polygamy), an absence of comorbid diseases (e.g., renal or liver failure, diabetes mellitus, hypertension, hyperlipidemia and coronary heart disease), no history of a major pelvic trauma, no history of psychiatric or neurological disorder, no alcoholism, no illicit drug abuse, and nonuse of drugs (e.g., phosphodiesterase type 5 inhibitors and antidepressant drugs) that could affect sexual function. Age, age at first marriage (for both genders), monthly wage, educational level and employment status were determined as control variables.

\section{Questionnaires and data collection}

A door-to-door survey was conducted, and data were collected from 45 monogamous men and 35 polygamous men. The International Index of Erectile Function QuestionnaireErectile Function Domain (IIEF-EFD) was used to determine the erectile status of participants. To evaluate the psychological status of all participants, we used the Beck Depression Inventory (BDI) consisting of 21 questions, in conjunction with a sociodemographic survey (7). BDI has the ability to assess psychological and physical symptoms like mood, pessimism, sense of failure, self-dissatisfaction, guilt, punishment, selfdislike, self-accusation, social withdrawal, body image, work difficulties, loss of libido, fatigue, appetite, weight loss, bodily preoccupation, and insomnia. The sociodemographic survey comprised 44 questions (constructed by authors) evaluating: education levels, employment, and insurance statuses of men and women; duration of marriages, relations of kinship between the men and their wives, the presence and number of children, and drug use. The IIEF-EFD score was calculated as the sum of the scores for questions $1-5$ and $15(8,9)$. IIEF erectile function scores were classified as normal $(>21)$, mild erectile dysfunction (ED) (16-21), moderate ED (11-15), and severe ED $(<11)$. BDI was applied to all participants under the supervision of a counselor physician. Scores from 0-13 indicated no depression, scores from 14-24 indicated medium depression, and scores equal to and above 25 represented serious depression according to the Beck depression scale. 


\section{Statistical analysis}

Data were expressed as mean standard deviations or as medians and ranges. The dependent variables were IIEF-EFD and BDI score values. Marriage type (polygamy or monogamy) was the only independent variable. A nonparametric Mann-Whitney test was performed to compare continuous variables between groups as the $\mathrm{p}$ value did not show normal distributions according to the Kolmogorov-Smirnov test. Odds ratios (OR), 95\% confidence intervals (CI), Chi-square tests and Fisher's exact test were used where necessary. All calculations were performed using Statistical Package for the Social Sciences version 20.0 (IBM SPSS Statistics; Armonk, NY, USA). All statistical tests were two-sided, and $\mathrm{p}<0.05$ was considered statistically significant.

\section{RESULTS}

The polygamous group consisted of 35 men whose median age was 48.0 years (min-max: 27.0-78.0), while the monogamous group consisted of 45 men whose median age was 46.0 years (min-max: 36.0-71.0). Median age at first marriage of polygamous men was 23.0 years (min-max: 19.0-33.0), while it was 24.0 years (min-max: 18.0-36.0) for monogamous men $(\mathrm{p}>0.05)$. Median age at marriage of the first wives of polygamous men was 20 years (min-max: 18.0-28.0), while median age at marriage of wives of monogamous men was 21 years (min-max: 17.0-29.0) $(\mathrm{p}>0.05)$. There were no statistically significant differences in terms of sociodemographic factors between the groups (Tables 1-3).

Compared with monogamous men, polygamous men had considerably higher IIEF-EFD scores $(\mathrm{p}<0.05)$. The median IIEF-EFD score was 25.0 for polygamous men, while the median IIEF-EFD score was 22.0 for monogamous men. A comparison of BDI scores in the two groups showed that polygamous men had lower BDI scores, but the difference between the two groups was statistically non-significant ( $>0.05$ ) (Table 4). Similar results were achieved, when degrees of erectile dysfunc- tion and depression data were explored by using cross tables with Chi-squared tests, odds ratios and $95 \%$ confidence intervals of odds ratios (Table 5). Monogamous men were more likely to experience any degree of erectile dysfunction and depression. Odds ratios and 95\% confidence intervals for erectile dysfunction and depression were 14.4 (95\% CI: 3.1-67.5) and 7.4 (95\% CI: 0.961.9), respectively. Because the confidence interval includes 1 , the odds ratio of depression was not statistically significant.

More than one third (36.4\%) of polygamous men had been married to their second wives for at least 16 years. Love, cited as one of the reasons for marriage, was ranked second by polygamous men. The most frequent reason given by these men for multiple marriages was their sex drive. The main reasons for multiple marriages reported by polygamous men were, in descending order: 1) a wife's decreased capability of satisfying the man's sexual desires (37.1\%); 2) falling in love with the second wife (22.8\%); and 3) incompatibility with the first wife $(17.1 \%)$ (Table 6).

TABLE 1. Comparison of selected demographic features of polygamous and monogamous men

\begin{tabular}{lccc}
\hline Features & $\begin{array}{c}\text { Polygamous } \\
\text { Men }(\mathrm{n}=35)\end{array}$ & $\begin{array}{c}\text { Monogamous } \\
\text { Men }(\mathrm{n}=45)\end{array}$ & $\mathrm{p}$ \\
\hline $\begin{array}{l}\text { Age in years (mean } \pm \text { SD) } \\
\text { (min.-med.-max.) }\end{array}$ & $\begin{array}{c}49.9 \pm 12.8 \\
(27.0-48.0-78.0)\end{array}$ & $\begin{array}{c}49.02 \pm 10.3 \\
(36.0-46.0-71.0)\end{array}$ & $>0.05^{\mathrm{a}}$ \\
Cigarette smoking (n, \%) & & & \\
Ongoing & $11(31.4 \%)$ & $13(28.8 \%)$ & \\
Ex-smoker & $6(17.1 \%)$ & $9(20.0 \%)$ & $>0.05^{\mathrm{b}}$ \\
Never-smoker & $18(51.5 \%)$ & $23(51.2 \%)$ & \\
Monthly wage $(\mathrm{n}, \%)$ & & & \\
0-500 USD & $16(45.7 \%)$ & $24(53.3 \%)$ & \\
501-1000 USD & $9(25.7 \%)$ & $10(22.2 \%)$ & $>0.05^{\mathrm{b}}$ \\
$\geq 1001$ USD & $10(28.6 \%)$ & $11(24.5 \%)$ & \\
\hline
\end{tabular}

ann-Whitney U test was used.

${ }^{\mathrm{b}} \mathrm{Chi}$-Square test was used.

${ }^{\mathrm{c}}$ The minimum monthly wage in Turkey was around 400 USD during the data collection period.

TABLE 2. Comparison of educational levels of men and their wives in polygamous and monogamous marriages

\begin{tabular}{|c|c|c|c|c|c|c|c|}
\hline \multirow[b]{2}{*}{ Level of Education (n, \%) } & \multicolumn{2}{|c|}{ Men } & \multirow[b]{2}{*}{$\mathrm{p}$} & \multicolumn{3}{|c|}{ Wives } & \multirow[b]{2}{*}{$\mathrm{p}$} \\
\hline & $\begin{array}{l}\text { Polygamy } \\
(\mathrm{n}=35)\end{array}$ & $\begin{array}{c}\text { Monogamy } \\
(\mathrm{n}=45)\end{array}$ & & $\begin{array}{l}\text { First wife } \\
(\mathrm{n}=35)\end{array}$ & $\begin{array}{l}\text { Second wife } \\
\quad(\mathrm{n}=35)\end{array}$ & $\begin{array}{c}\text { Sole wife } \\
(\mathrm{n}=45)\end{array}$ & \\
\hline Low $^{a}$ & $23(65.7)$ & $26(57.8)$ & & $33(94.3)$ & $27(77.1)$ & $37(82.2)$ & \\
\hline Middle $^{\mathrm{b}}$ & 10 (28.6) & $14(31.1)$ & $>0.05^{\mathrm{d}}$ & $2(5.7)$ & $6(17.1)$ & $6(13.3)$ & $>0.05^{\mathrm{c}}$ \\
\hline High $^{c}$ & $2(5.7)$ & $5(11.1)$ & & $0(0.0)$ & $2(5.8)$ & $2(4.5)$ & \\
\hline
\end{tabular}

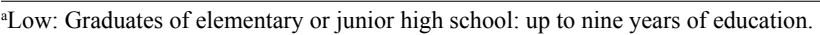

${ }^{b}$ Middle: Graduates of high school (lyceum) or technical-vocational school: up to 12-14 years of education.

"High: Graduates of university, college or postgraduate programs: more than 14 years of education.

'For the Chi-square test to be valid, the "middle" and "high" rows were combined. 
TABLE 3. Comparison of employment status of men and their wives within polygamous and monogamous marriages

\begin{tabular}{|c|c|c|c|c|c|c|c|}
\hline \multirow[t]{2}{*}{ Employment Status (n, \%) } & \multicolumn{2}{|c|}{ Men } & \multicolumn{5}{|c|}{ Wives } \\
\hline & $\begin{array}{l}\text { Polygamy } \\
(\mathrm{n}=35)\end{array}$ & $\begin{array}{l}\text { Monogamy } \\
\quad(\mathrm{n}=45)\end{array}$ & $\mathrm{p}$ & $\begin{array}{l}\text { First wife } \\
(\mathrm{n}=35)\end{array}$ & $\begin{array}{c}\text { Second wife } \\
(\mathrm{n}=35)\end{array}$ & $\begin{array}{l}\text { Sole wife } \\
(\mathrm{n}=45)\end{array}$ & $\mathrm{p}$ \\
\hline Employed & $18(51.4)$ & $31(68.9)$ & & $2(5.7)$ & $2(5.7)$ & $4(8.8)$ & \\
\hline Self-employed & $7(20.0)$ & $5(11.1)$ & & $0(0.0)$ & $3(8.6)$ & $0(0.0)$ & \\
\hline Retired & $2(5.7)$ & $2(4.4)$ & $>0.05^{\mathrm{a}}$ & $0(0.0)$ & $0(0.0)$ & $0(0.0)$ & $>0.05^{\mathrm{a}}$ \\
\hline Not working outside the home & $8(22.9)$ & $7(15.6)$ & & $33(94.3)$ & $30(85.7)$ & $41(91.2)$ & \\
\hline
\end{tabular}

aFor the Chi-square test to be valid, the "Employed," - "Self-employed" and "Retired" - "Not working outside the home" rows were combined.

TABLE 4. Comparison of IIEF-EFD ${ }^{\mathrm{a}}$ scores and $\mathrm{BDI}^{\mathrm{b}}$ scores of polygamous and monogamous men

\begin{tabular}{|c|c|c|c|}
\hline Scales & $\begin{array}{l}\text { Polygamous } \\
\text { Men }(n=35)\end{array}$ & $\begin{array}{l}\text { Monogamous } \\
\text { Men }(n=45)\end{array}$ & $\mathrm{p}$ \\
\hline $\begin{array}{l}\text { IIEF-EFD scores (mean } \pm \text { SD) } \\
\text { (min.-med.-max.) }\end{array}$ & $\begin{array}{c}25.7 \pm 3.4 \\
(18.0-25.0-30.0)\end{array}$ & $\begin{array}{c}21.3 \pm 6.5 \\
(6.0-22.0-30.0)\end{array}$ & $<0.01^{\mathrm{c}}$ \\
\hline $\begin{array}{l}\text { BDI scores (mean } \pm \mathrm{SD}) \\
\text { (min.-med.-max.) }\end{array}$ & $\begin{array}{c}6.1 \pm 5.3 \\
(0.0-5.0-30.0)\end{array}$ & $\begin{array}{c}8.5 \pm 8.1 \\
(0.0-7.0-43.0)\end{array}$ & $>0.05^{\mathrm{a}}$ \\
\hline
\end{tabular}

TABLE 5. Distribution of polygamous and monogamous men according to degrees of erectile dysfunction based on IIEF-EFD ${ }^{\mathrm{a}}$ scores and to degrees of depression based on $\mathrm{BDI}^{\mathrm{b}}$ scores

\begin{tabular}{|c|c|c|c|c|c|}
\hline \multirow[t]{2}{*}{$\begin{array}{l}\text { Marriage } \\
\text { Type (n, \%) }\end{array}$} & \multicolumn{4}{|c|}{ Degree of Erectile Dysfunction } & \multirow[t]{2}{*}{$\begin{array}{c}\mathrm{p} \\
\text { OR }(95 \% \mathrm{CI})^{\mathrm{c}}\end{array}$} \\
\hline & Normal & Mild & Moderate & Severe & \\
\hline olygamy & $33(94.3)$ & $2(5.7)$ & $0(0.0)$ & $0(0.0)$ & $<0.001$ \\
\hline my & $(53.3)$ & $13(28.9)$ & $5(11.1)$ & $3(6.7)$ & $14.4(3.1-67.5)^{\mathrm{d}}$ \\
\hline \multicolumn{6}{|c|}{ Degree of Depression } \\
\hline & No Dep & ression & Medium & Serious & \\
\hline olygamy & $34(9$ & & $0(5.7)$ & $1(2.9)$ & $>0.057 .4$ \\
\hline Ionogamy & 37 & & $6(13.3)$ & $2(4.4)$ & $(0.9-61.9)^{\mathrm{e}, \mathrm{f}}$ \\
\hline \multicolumn{6}{|c|}{$\begin{array}{l}\text { "International Index of Erectile Function Questionnaire-Erectile Function Domain } \\
\text { "Beck Depression Inventory } \\
\text { 'Odds ratio ( } 95 \% \text { confidence interval) } \\
\text { 'For the Chi-square test to be valid and to be able to calculate odds ratio, the "Mild" - } \\
\text { "Moderate" - "Severe" rows were combined. } \\
\text { "For the Chi-square test to be valid and to be able to calculate odds ratio, the "Medium" } \\
\text {-"Serious" rows were combined. } \\
\text { "Fisher's exact test was used. }\end{array}$} \\
\hline
\end{tabular}

According to our results, first marriages were usually civil $(81.8 \%)$. The majority of the first and second wives of polygamous men, and the wives of monogamous men, were not working outside the home $(94.3 \%, 85.7 \%$, and $91.2 \%$, respectively) (Table 4). While the proportion of polygamous men who had kinship relations with their first wives was $45.5 \%$, this proportion was less than $10 \%$ in the case of second wives. Of the 45 monogamous men, 25 (55.5\%) had bonds of kinship with their wives. A total of 27 out of 35 (77.1\%) of the women
TABLE 6. Distribution of reasons for second marriages among polygamous men

\begin{tabular}{lcc}
\hline Reasons for marriage $(\mathrm{n}=35)$ & $\mathrm{n}$ & $\%$ \\
\hline Love & 8 & 22.8 \\
Having a baby & 2 & 5.7 \\
Sexual drive & 13 & 37.1 \\
Incompatibility with first wife & 6 & 17.1 \\
Sexually unwilling wife & 3 & 8.6 \\
To gain ascendancy over other people (by having sons) & 3 & 8.6 \\
\hline
\end{tabular}

who agreed to become second wives had married for the first time. All of the wives of polygamous men knew each other. Before marriage, 33 out of 35 second wives (94.3\%) knew that their husbands were married to other women. More than half of the wives of polygamous men lived in separate houses. Half of the polygamous men allocated days for each wife in a particular order such as single or double days in a month, or one week with the first wife and one week with the other wife. A total of $62.9 \%$ of polygamous men responded negatively to the question: "Would you recommend polygamous marriage to other men?" While all the polygamous men had children from their first wives, $71.4 \%$ of them also had children from their second wives. Marrying another woman for the purpose of bearing a child appeared to be an uncommon reason for polygamous marriage. Additionally, among polygamous men, $85.7 \%$ and $94.3 \%$, respectively, reported a good rapport between one wife's children and the other wife.

\section{DISCUSSION}

Polygamy is accepted as a well-established institution that dates from ancient times. Most societies in the anthropological records permit men to marry multiple wives (10). Having multiple wives has always been positively associated with status and wealth, even among highly egalitarian foraging societies (11). 
Historically, many factors are thought to have perpetuated polygamy. Dorjahn (12) hypothesized that men had higher mortality rates than women as a result of disease, warfare, and the occupational dangers associated with hunting and fishing. From this perspective, we can speculate that the higher mortality rates of men may have led to an increase in polygamous marriages (13). Previous studies have offered several explanations for men's preference for polygamous marriage such as increased prestige within the community, satisfaction of sexual desires, the ability to have as many children as desired, and an expanded work force $(14,15)$. Similarly, our participants ranked the reasons for having multiple wives in the following order: satisfaction of sexual desires; falling in love with another woman; and decreased compatibility with the senior wife. In Turkey, the failure of the senior wife to bear a child was thought to be a common reason for second marriage. However, our study revealed that although the polygamous men had children from their first wives, they also initiated second marriages. Child bearing was uncommon among the reasons given for polygamy, as only $4.5 \%$ of the men initiated additional marriages for this purpose. Moreover, polygamous men explained that they chose widowed women as second wives to provide them with a social safety net.

Polygamous marriage is indeed regulated and limited by laws in most countries. However, it is generally accepted in some societies. Similar to most governments, the Turkish government abolished polygamy, which was officially criminalized with the adoption of the Turkish Civil Code in 1926. However, it is still practiced, mostly in the southeastern part of Turkey.

The literature on polygamous marriages has largely focused on its psychosocial and emotional functions, and life/marital satisfaction in relation to women. These marriages are generally associated with increased stress, tension, and disparity within the family structure $(6,16)$. Women within polygamous marriages often experience varying degrees and types of emotional difficulties such as anger, jealousy, competition, loneliness, unhappiness, and a lack of intimacy with their spouses (17). These experiences have been attributed to competition among co-wives, a considerable spousal age gap, decreased relatedness within households, and reduced certainty of paternity. Infertility and fear of divorce were found to be the reasons why most women allowed co-wives into their marriages $(18,19)$. Al-Issa (20) has identified polygamous marriage as a marker of increased family stress that may contribute to mental illness in mothers and children within polygamous families. Women within polygamous families showed more mental health problems than women within monogamous families (21).
A few Turkish studies have evaluated mental health aspects of women within polygamous marriages. Özer et al. (22) investigated BDI scores for polygamous and monogamous women. They found that polygamous women had higher scores compared with monogamous women. Another study from Turkey that compared mental health aspects of polygamous and monogamous women revealed that polygamous women experienced more somatization disorders and psychological distress (23). In addition to women, adolescents from polygamous families have reported lower self-esteem, increased family dysfunction, and decreased economic status and academic achievement. Al-Krenawi et al. (24) also compared psychological functions and marital and life satisfaction of polygamous and monogamous women in Jordan. They noted that polygamous women reported decreased self-esteem, less life satisfaction, and higher depression, anxiety, and hostility compared with monogamous women.

Polygamous marriages also reduce the overall male parental investment by eliminating opportunities for low-status males to establish pair-bonds (and invest in offspring), decreasing the investment per child within larger families, and shifting investments of high-status males from their offspring toward obtaining more long-term mates (16). The net effect of polygyny on male parental investment is often a reduction in the average investment per child.

Since studies have generally evaluated polygamy in relation to women, there is a paucity of data on its psychosexual function and mental health in relation to men within these marriages. In one study, an inverse correlation between the number of wives and the severity of ED was noted among Nigerian men (25). Gray et al. (26) also reported an inverse relationship between the number of wives and ED in northern Kenya. However, no study evaluating depressive symptoms of Turkish men within polygamous marriages has been reported to date.

The main strength of our study is that it provides preliminary objective data on psychosexual functions of polygamous and monogamous men, which were evaluated using validated scales. A comparative analysis of men in both groups was also performed.

The present study has demonstrated that polygamous men have significantly higher IIEF-EFD scores compared with monogamous men. Additionally, polygamous men have lower BDI scores, but the difference between groups is not statistically significant. According to our results, although jealousy, emotional distress, and unhappiness are recurring themes that may have negative effects on the lives of women and children within polygamous families, men within these families have lower depression scores and higher erectile function scores than monogamous men. The reason for this may be the lon- 
ger duration of monogamous marriage, which may reduce the sexual attraction between partners. BDI scores were higher among those men who did not engage in extramarital affairs. Contrary to our results, some researchers have linked polygamy to several negative effects on men. They have shown that polygamous men were more likely to suffer from alcoholism, which was attributed to psychological problems (4). Al-Krenawi et al. (16) reported that the educational level of polygamous men was also significantly lower than that of monogamous men. Our results support the findings of Al-Krenawi (16), but this difference was not statistically significant.

Although our study revealed that polygamous men had lower depression scores, interestingly, $62.9 \%$ of these men responded negatively to the question "Would you recommend polygamous marriage to other men?" Exploring the reasons for this surprising response may motivate researchers in this field to conduct further studies that exclusively address men.

There were several limitations to the present study. Considering polygamous men as a special population, a non-probability sampling technique was used. The population size was unknown and the sample size was relatively small.

In a cross-sectional study design, it is difficult to clarify whether higher IIEF-EFD scores or lower BDI scores of polygamous men were a cause or effect. Further studies on this area with stronger methodologies may be helpful to determine the causation.

In this study, we cannot exactly assert that we compared the IIEF-EFD scores of men with multiple sexual partners and men with a single sexual partner. In the society in which we conducted our study, extramarital sexual relations are not approved, while polygamy is considered more favorable. Therefore, concerned that their answer may not be truthful, we did not ask the question "Do you have sexual partners other than your wife?" to monogamous men. Therefore, our results should be carefully interpreted in light of these limitations.

In summary, although our results demonstrated that polygamous men had higher erectile function and lower depression scores than monogamous men, further research determining the effects of a polygamous marital structure on behavioral, mental, sexual and emotional adjustments in men is warranted. Furthermore, studies addressing the perspectives of offspring and the expectations of women within polygamous marriages should be conducted. Our results provide preliminary data for future research in this field.

Ethics Committee Approval: Ethics committee approval was received for this study from the ethics committee of Kahramanmaraş Sütçü İmam University School of Medicine (Date of approval: 15 April 2011; number: 2011-02/4).

Informed Consent: Written informed consent was obtained from participants who participated in this study.
Peer-review: Externally peer-reviewed.

Author contributions: Concept - H.C.E., S.R.; Design - H.C.E., S.R., O.A.; Supervision - H.C.E., S.R., O.A.; Resource - S.R., E.E., M.R.B.; Materials - E.E., O.A., M.R.B., F.K., C.B.; Data Collection and/or Processing - E.E., M.R.B., O.A.; Analysis and/or Interpretation - H.C.E., S.R., O.A.; Literature Search - E.E., M.R.B., O.A.; Writing - M.R.B., F.K., C.B., H.C.E.; Critical Reviews - F.K., C.B., E.E., H.C.E.

Conflict of Interest: No conflict of interest was declared by the authors.

Financial Disclosure: The authors declared that this study has received no financial support.

\section{REFERENCES}

1. Al-Krenawi A, Slonim-Nevo V. Psychosocial and familial functioning of children from polygynous and monogamous families. J Soc Psychol 2008;148:745-64. [Crossref]

2. Al-Krenawi A, Graham JR. Helping Professional practice with indigenous peoples: The Bedouin-Arab case. Lanham, MD: University Press of America; 2009.

3. Brooks T. The problem with polygamy. Philosophical Topics 2009;37:109-22. [Crossref]

4. Olley BO. Predictors of Hazardous and Harmful Alcohol Use among Nigerian Freshmen. African J Med Sci 2004;33:327-33.

5. Read N. "The hidden wives of Turkey". BBC News 2005-08-30. Accessed 2014-09-16.

6. Al-Krenawi A. Family therapy with a multiparental/multispousal family. Family Process 1998;37:65-82. [Crossref]

7. Basker M, Moses PD, Russell S, Swamidhas P, Russell S. The psychometric properties of Beck Depression Inventory for adolescent depression in a primary-care paediatric setting in India. Child Adolesc Psychiatry Ment Health 2007;1:1-7. [Crossref]

8. Rosen RC, Riley A, Wagner G, Osterloh IH, Kirkpatrick J, Mishra A. The international index of erectile function (IIEF): a multidimensional scale for assessment of erectile dysfunction. Urology 1997;49:822-30. [Crossref]

9. Cappelleri JC, Rosen RC, Smith MD, Mishra A, Osterloh IH. Diagnostic evaluation of the erectile function domain of the International Index of Erectile Function. Urology 1999;54:34651. [Crossref]

10. White DR, Betzig L, Borgerhoff Mulder M, Chick G, Hartung J, Irons W, et al. Rethinking polygyny: co-wives, codes, and cultural systems (includes comments and author's reply). Curr Anthropol 1988;29:529-72. [Crossref]

11. Marlowe FW. The mating system of foragers in the standard crosscultural sample. Cross-Cult Res 2003;37:282-306. [Crossref] 
12. Dorjahn VR. The factor of polygyny in African demography. In: Bascom WR, Herskovits MJ, editors. Continuity and change in African cultures. University of Chicago Press, Chicago; 1959. 87-112.

13. Lee GR. Marital structure and economic systems. J Marriage Fam 1979;41:701-13. [Crossref]

14. Uchendu VC. Concubinage among Ngwa Igbo of Southern Nigeria. Africa 1965;35:187-97. [Crossref]

15. Hartung J. Polygyny and inheritance of wealth. Curr Anthropol 1982; 23:1-12. [Crossref]

16. Al-Krenawi A, Lightman ES. Learning achievement, social adjustment, and family conflict among Bedouin-Arab children from polygamous and monogamous families. J Soc Psychol 2000;140:345-56. [Crossref]

17. Henrich J, Boyd R, Richerson PJ. The puzzle of monogamous marriage. Philos Trans R Soc Lond B Biol Sci 2012;367:657-69. [Crossref]

18. Madhavan S. Best of friends and worst of enemies: Competition and collaboration in polygamy. Ethnology 2002;41:69-84. [Crossref]

19. Meekers D, Franklin N. Women's perception of polygyny among the Kaguru of Tanzania. Ethnology 1995;34:315-30. [Crossref]

20. Al-Issa I. Culture and mental illness in Algeria. Int J Soc Psychiatr 1990;36:230-40. [Crossref]
21. Al-Krenawi A, Slonim-Nevo V. Psychological and social functioning among Bedouin-Arabs in the Negev: Comparing polygamous and monogamous families. Final Scientific Report submitted to the National Social Security Office, Beer Sheva, Ben-Gurion University of the Negev 2002, Israel.

22. Özer A, Orhan FÖ, Ekerbiçer HÇ. Sociodemographic Variables and Depression in Turkish Women From Polygamous Versus Monogamous Families. Health Care Women Int 2013;34:102434. [Crossref]

23. Ozkan M, Altindag A, Oto R, Sentunali E. Mental health aspects of Turkish women from polygamous versus monogamous families. Int J Soc Psychiatr 2006;52:214-20. [Crossref]

24. Al-Krenawi A, Graham JR, Al Gharaibeh F. A Comparison Study of Psychological, Family Function Marital and Life Satisfactions of Polygamous and Monogamous Women in Jordan. Community Ment Health J 2011;47:594-602. [Crossref]

25. Oladiji F, Kayode OO, Parakoyi DB. Influence of socio-demographic characteristics on prevalence of erectile dysfunction in Nigeria. Int J Impot Res 2013;25:18-23. [Crossref]

26. Gray P, Campbell B. Erectile dysfunction and its correlates among the Ariaal of northern Kenya. Int $J$ Impot Res 2005; 17:445-9. [Crossref] 